\title{
Françoise Fery-Hue, Un séjour de Nicolas Volcyr au château de Comines. Trois œuvres inédites dédiées à Georges d'Halluin
}

\section{Filippo Fassina}

\section{(2) OpenEdition \\ Journals}

\section{Edizione digitale}

URL: http://journals.openedition.org/studifrancesi/5277

DOI: 10.4000/studifrancesi.5277

ISSN: 2421-5856

\section{Editore}

Rosenberg \& Sellier

\section{Edizione cartacea}

Data di pubblicazione: 1 dicembre 2016

Paginazione: 513-514

ISSN: 0039-2944

\section{Notizia bibliografica digitale}

Filippo Fassina, «Françoise Fery-Hue, Un séjour de Nicolas Volcyr au château de Comines. Trois œuvres inédites dédiées à Georges d'Halluin », Studi Francesi [Online], 180 (LX | III) | 2016, online dal 01 janvier 2017, consultato il 18 septembre 2020. URL : http://journals.openedition.org/studifrancesi/5277 ; DOI : https://doi.org/10.4000/studifrancesi.5277

Questo documento è stato generato automaticamente il 18 settembre 2020.

\section{cc) (†)}

Studi Francesi è distribuita con Licenza Creative Commons Attribuzione - Non commerciale - Non opere derivate 4.0 Internazionale. 


\title{
Françoise Fery-Hue, Un séjour de Nicolas Volcyr au château de Comines. Trois œuvres inédites dédiées à Georges d'Halluin
}

\author{
Filippo Fassina
}

\section{NOTIZIA}

FRANÇOISE FERY-HUE, Un séjour de Nicolas Volcyr au château de Comines. Trois œuvres inédites dédiées à Georges d'Halluin, «Bibliothèque d'Humanisme et Renaissance», LXXVII, 3, 2015, pp. 635-646.

1 Nicolas Volcyr fu dottore in teologia, maitre ès arts e lettore all'Università. Successivamente divenne segretario del duca Antoine de Lorraine, di cui fu lo storico ufficiale. Tra le sue opere più importanti vengono ricordate un trattato sulla musica gregoriana del 1501, un'epopea sulla gloria del duca di Lorraine del 1526 (L'histoire et recueil de la triomphante et glorieuse victoire obtenue contre les séduits et abusés luthériens), alcuni trattati di polemica religiosa e di storia. Fu traduttore di testi devozionali e di scritti a carattere storico.

2 In questo studio vengono analizzate tre opere latine rimaste inedite e dedicate a uno dei suoi mecenati più importanti, l'umanista Georges d'Halluin, signore di Comines. I tre testi, che si configurano come trattati sulla tecnica poetica contenuti nel manoscritto della Bibliothèque Nationale de France (lat. 16692), sono la Catulliana odegraphia (detta odegraphia prima), l'odegraphia Horatiana (detta odegraphia secunda) e il De metrorum divisione. L'A. sottolinea che il manoscritto non contiene soltanto le tre opere di Volcyr, ma anche altre opere brevi di varia natura, riunite senza uno schema apparente. Potrebbe trattarsi di un mélange redatto proprio da Georges d'Halluin, sulla base di altre raccolte contenute nella sua biblioteca. Interessanti sono poi le 
annotazioni autografe del mecenate, che vanno dalla semplice indicazione di un autore citato ad appunti sulla metrica o a considerazioni sui testi. Resta tuttavia l'incognita posta in conclusione di questo studio sul motivo per cui i tre testi di Volcyr rimangano a tutt'oggi inediti. 